\title{
RESEARCH
}

Open Access

\section{Equine-assisted interventions for veterans with service-related health conditions: a systematic mapping review}

\author{
Adam R. Kinney ${ }^{1 *}$, Aaron M. Eakman ${ }^{1}$, Rebecca Lassell ${ }^{1,2}$ and Wendy Wood ${ }^{2}$
}

\begin{abstract}
Background: Evidence-based treatments for service-related health conditions such as posttraumatic stress disorder (PTSD), depression, and traumatic brain injury (TBI) are not effective for all veterans. Equine-assisted interventions are emerging as an additional treatment modality, but little is known regarding the safe and effective delivery of these interventions. This study aimed to describe the following features of the body of literature concerning equine-assisted interventions among veterans: 1) veterans who have participated in equine-assisted interventions; 2) specific characteristics of equine-assisted interventions in veterans; and 3) the specific characteristics of research on equine-assisted interventions in veterans.
\end{abstract}

Methods: We conducted a systematic mapping review of peer-reviewed literature reporting on equine-assisted interventions among veterans between 1980 and 2017. Searches of nine databases yielded 3336 unique records, six of which met the inclusion criteria and were reviewed. Data relevant to the study aims were extracted and analyzed.

Results: Equine-assisted interventions among veterans disproportionately targeted psychosocial outcomes and yielded promising results. The detailed methods of EAI varied in the reported studies, ranging from communicating with the horse to mounted exercises. There was also great diversity in outcome measurement. The state of theoretical development regarding the mechanisms by which equine-assisted interventions benefit the veteran population is currently underdeveloped. Studies provided insufficient detail with respect to the description of the intervention, reasons for attrition, and the dose-response relationship.

Conclusions: Scientific development of equine-assisted interventions targeting psychosocial outcomes among veterans is warranted to establish their efficacy. Targeted outcomes should be expanded, including outcomes more closely aligned with the nature of polytraumatic injuries. Future research must also emphasize the theoretical development of equine-assisted interventions for veterans and thoroughly describe the participants, components of the intervention, factors contributing to attrition, and optimal dose-response relationships.

Keywords: Veterans, Service-related injuries, Equine-assisted interventions, Posttraumatic stress disorder, Systematic mapping review

\footnotetext{
* Correspondence: Adam.Kinney@colostate.edu

'Department of Occupational Therapy, Colorado State University, Fort Collins,

CO 80523, USA

Full list of author information is available at the end of the article
}

(c) The Author(s). 2019 Open Access This article is distributed under the terms of the Creative Commons Attribution 4.0 International License (http://creativecommons.org/licenses/by/4.0/), which permits unrestricted use, distribution, and reproduction in any medium, provided you give appropriate credit to the original author(s) and the source, provide a link to the Creative Commons license, and indicate if changes were made. The Creative Commons Public Domain Dedication waiver (http://creativecommons.org/publicdomain/zero/1.0/) applies to the data made available in this article, unless otherwise stated. 


\section{Background}

In the wake of the terrorist attacks on September 11, 2001, approximately 2.77 million service members were deployed to combat zones in support of Operation Enduring Freedom, Operation Iraqi Freedom, and/or Operation New Dawn [1]. Due to psychological and physical trauma incurred during combat deployments, an influx of veterans has returned to the civilian community with polytraumatic injuries or complex conditions characterized by unpredictable combinations of two or more health-related diagnoses [2]. For example, those deployed to combat zones tend to experience high rates of traumatic brain injury (TBI, 10-20\%), posttraumatic stress disorder (PTSD, 5.6-30.5\%), and depression (5.6$16 \%$ ), which tend to co-occur and pose serious threats to veterans' cognitive and emotional functioning [3, 4]. Furthermore, the physical capacities of veterans are threatened by somatic symptoms (e.g., pain or fatigue) associated with the above conditions, as well as acquired spinal cord injuries, musculoskeletal injuries, and/or amputations $[2,3,5]$.

The complex constellation of cognitive, emotional, and physical impairments experienced by veterans with polytraumatic injuries poses significant barriers to successful community reintegration $[2,6]$. Veterans with TBI, PTSD, and/or depression experience difficulties with establishing supportive and close connections with others $[7,8]$. Furthermore, veterans with polytraumatic injuries experience limited engagement in community-based activities, thereby compromising their successful transition to civilian life $[9,10]$. Veterans report that cognitive and emotional impairments associated with these conditions foster a tendency to avoid community-based activities in the community given the presence of others $[11,12]$ and that physical symptoms (e.g., pain or fatigue) disrupt veterans' participation in typical patterns of activity [11, 13].

The development of treatments for service-related health conditions such as PTSD, depression, and TBI has notably progressed. For example, symptoms of PTSD have been shown to improve in response to both exposure-based therapy [14] and cognitive processing therapy [15]. These treatments are not effective for all veterans, however. Evidence suggests, for instance, that a significant proportion of participants continue to meet diagnostic criteria for PTSD despite receiving established treatments such as exposure-based therapy $[15,16]$. Furthermore, these treatments tend to target service-related health conditions in isolation, and as such, there is a significant need for additional approaches that transcend specific diagnoses and are tailored to address the multifaceted concerns of veterans with polytraumatic injuries [17]. The formidable challenges associated with polytraumatic injuries thus warrant the application of interventions that are similarly complex, such as equineassisted interventions.

\section{Equine-assisted interventions}

The term animal-assisted interventions (AAIs) is a commonly used umbrella term that encompasses a plethora of ways in which different species of animals are beneficial to people [18]. Equine-assisted interventions, another umbrella term, comprise a growing subset of AAIs and encompass both equine-assisted activities (EAAs) and equine-assisted therapies (EATs). Broadly speaking, EAAs involve horses, clients, participants, volunteers and instructors affiliated with an equine center in mounted activities on a horse, as well as unmounted activities such as grooming, tacking or caring for a horse [19]. Whereas EATs also integrate activities involving horses, credentialed health professionals design, deliver, or direct these goal-directed interventions in accord with their professions' respective scopes and standards of practice [19].

Between 2009 and 2016, the number of equine centers accredited by the Professional Association of Therapeutic Horsemanship International (PATH Intl) providing services to veterans grew from 89 to 335 centers, which is more than a three-fold increase [20]. Based on research of equine-assisted interventions for other populations [21,22], the services that these equine centers offered to veterans were presumably complex in nature; that is, they comprised complex interventions. Complex interventions include but are not limited to the following features: 1) the presence of several interacting components, 2) the ability to easily tailor the intervention to meet appropriate objectives, and 3) the capability of addressing highly variable outcomes [23]. Due to these features, complex interventions may be uniquely situated to address the multifaceted and heterogeneous nature of challenges associated with polytraumatic injuries among veterans [2]. Indeed, equine-assisted interventions for civilian populations with conditions often experienced by veterans have shown promising results, suggesting that they could yield similarly positive results among veterans. For example, therapy involving horses has been found to improve 1) function for those with traumatic brain injury [24], 2) psychosocial outcomes for those with depression [25], 3) psychological well-being among those with spinal cord injuries [26] and 4) symptoms of PTSD [27].

Considered altogether, the proliferation of EAAs and EATs for veterans with service-related health conditions begs for deliberate efforts aimed at advancing their theoretical and empirical bases. To the best of our knowledge, however, relevant peer-reviewed literature has not been systematically collected, categorized, described, and synthesized. Prior to evaluating complex interventions 
such as equine-assisted interventions, it is critical that a systematic review of the evidence germane to the intervention and its intended population is conducted [23]. In pursuit of this outcome, the present study has three specific aims:

1) To describe the characteristics of veterans (i.e., health conditions, gender, and age) who have participated in equine-assisted interventions.

2) To describe the specific features of equine-assisted interventions which have been applied to the veteran population, including the (a) prevalence of specific types of EAA and EAT, (b) intervention components, (c) providers, and (d) length, frequency, and/or duration of intervention sessions.

3) To describe the specific characteristics of research on equine-assisted interventions in the veteran population, including the (a) study designs, (b) reported outcomes and benefits, and (c) theoretical explanations of benefits.

\section{Methods}

Representing one of the 14 types of reviews in the family of systematic review research, systematic mapping reviews are a method of choice when research in a focused area of inquiry is early in scientific development but has yet to be systematically gathered, described, and categorized, in short, mapped [28, 29]. Researchers conducting systematic mapping reviews employ a broad scope, drawing from research reports with varying degrees of rigor to construct detailed classifications of a particular body of literature. While the quality of evidence is not assessed in a systematic mapping review, the employment of such a broad scope makes this method of review ideal when summarizing areas of inquiry in the early stages of development, including inquiry concerning the development and evaluation of complex interventions [23]. Systematic mapping reviews require the application of three filters to the existing literature: 1 ) gathering the literature, 2) selecting papers for inclusion, and 3) extracting information from selected papers that correspond to specific research aims.

\section{Search method}

The search procedure for the present study is consistent with the search procedure reported in previously developed papers [21,30]. Using approximately 45 search criteria and beginning in 2015, a library scientist developed and executed four comprehensive searches in the following databases to assist in multiple projects regarding equine-assisted activities or therapies: $\mathrm{CAB}$ Abstracts (EBSCO), CINAHL (EBSCO), PsycINFO (EBSCO), PubMed (NCBI), Social Sciences Abstracts (EBSCO), Social Services Abstracts (ProQuest), Social Work
Abstracts (EBSCO), SPORTDiscus (EBSCO), and Web of Science (Thomson Reuters). The final search was conducted in spring 2018 to retrieve papers published through 2017. The results of all searches were integrated into one EndNote library for screening, which facilitates efficient organization and management of references [31]. The search procedure yielded 3336 unique records.

\section{Application of inclusion and exclusion criteria}

Three reviewers reviewed papers for inclusion and exclusion criteria in two phases. In phase one, we applied the following inclusion criteria: papers were 1) primarily focused on one or more equine-assisted activity or therapy, 2) peer-reviewed, 3) a primary source, 4) written in English, and 5) published between 1980 and 2017. The reviewers blindly analyzed $20 \%$ of all sources initially retrieved, achieving 95\% agreement on their respective inclusion or exclusion decisions. Reviewers subsequently applied inclusion and exclusion criteria to the 3336 unique records, plus reviewed the reference lists of included papers for other relevant articles. This yielded an additional 180 unique records. Of the 3516 unique records identified through the search procedure and manual searching of reference lists, 506 remained after the first phase of review.

In phase two, we applied additional exclusion criteria to further reduce the 506 papers. Specifically, papers were excluded if 1) $20 \%$ or more of the participants were not military veterans or 2) the paper provided a synopsis of an EAAT-related study published elsewhere. Application of the above criteria reduced the 506 records to eight records pertaining to EAAT for veterans. These eight records were composed of six original research reports and two conceptual or descriptive papers. We extracted data from the six original research reports to address the specific aims of this systematic mapping review (Fig. 1).

\section{Extraction of data}

Consistent with the established protocol for systematic mapping reviews [32], we constructed a data extraction tool (DET) to facilitate the extraction of information relevant to each study aim.

\section{Aim 1}

We applied the DET to extract information related to: 1 ) age, 2) proportion of males, 3) health conditions of participants, and 4) assessment tools used to describe participants.

\section{Aim 2}

We employed the DET to extract information related to: 1) the specific type of EAA or EAT studied, 2) participant goals, 3) specific components of the intervention, 4) 


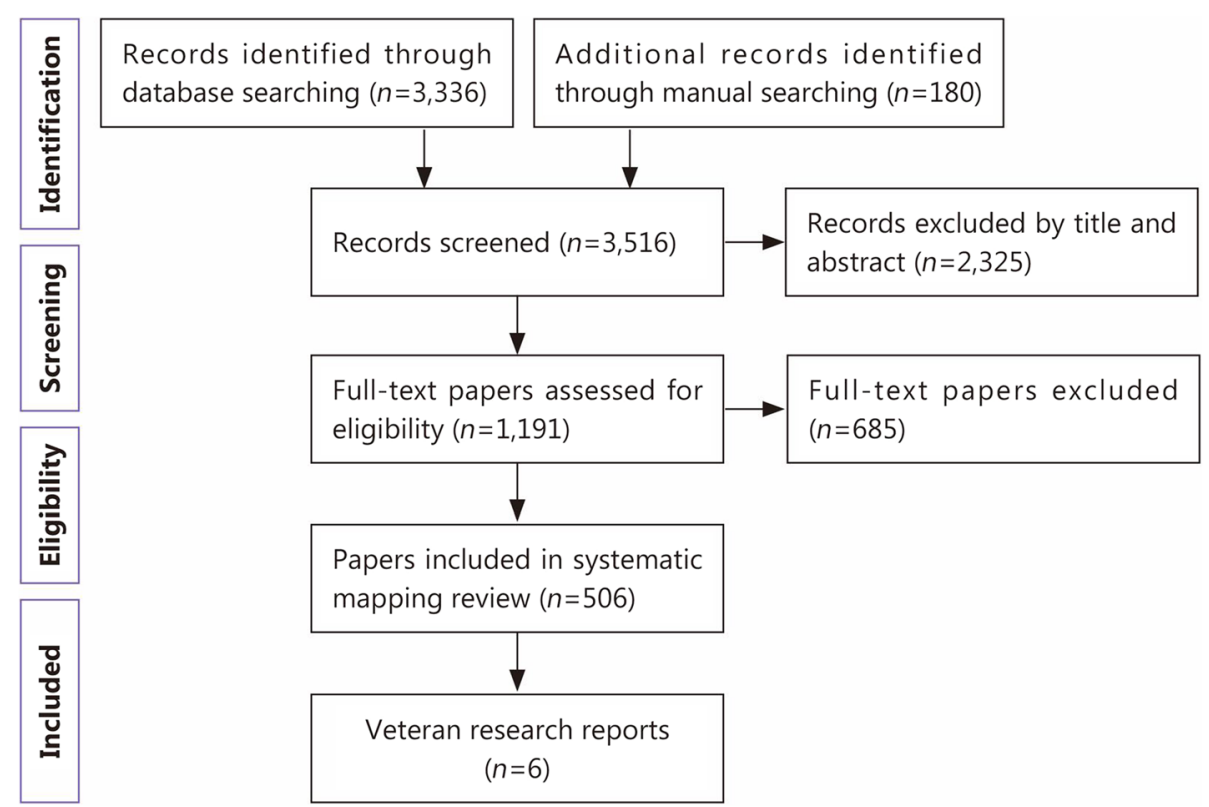

Fig. 1 Flow diagram of systematic mapping review and included studies

direct providers of the intervention, and 5) lengths and frequencies of individual sessions and overall duration of the intervention.

\section{Aim 3}

We applied the DET to extract information related to: 1 ) theoretical propositions proffered to explain the benefits of interventions, 2) research aims, 3) research approach (e.g., quantitative, qualitative, mixed or multi-methods), 4) specific research design (e.g., one group pre-post design), 5) method of measurement (e.g., interview, standardized assessment), and 6) reported outcomes.

Also related to Aim 3, the DET provided guidelines for sorting reported outcomes into broad categories. Four of these broad categories classified the focus of targeted outcomes: 1) body functions, 2) activity and participation, 3) symptoms of mental disorders, and 4) other outcomes. The International Classification of Functioning, Disability, and Health (ICF) defines body functions (ICF-BF) as physiological functions of the body (e.g., cognitive functions such as attention), activity as the performance of a particular task or action, and participation as "involvement in a life situation" (p. 10) [33]. The DET combined activity and participation into one level of functioning, ICF-A/P, because distinctions between activity and participation are difficult to establish [33]. The category symptoms of mental disorders was derived from the Diagnostic and Statistical Manual of Mental Disorders, Fifth Edition (DSM-V) [34]. The category other outcomes included outcomes that did not align with the above three broad categories (e.g., learning about oneself). Three other broad categories were used to sort outcomes based on the nature of the reported findings: 1) statistically significant findings or findings that reflected hypothesized positive outcomes and included supporting statistical evidence, 2) other positive findings or findings reported as clinically important but did not include statistical evidence to support their existence, and 3) negative findings or findings that were not reported as statistically significant or clinically important.

A research consultant entered the finalized DET into a Microsoft Access database. Using this database, the last author directed a training process that produced a minimum of $90 \%$ agreement on use of the DET across six reviewers. Inter-rater reliability was also supported by the establishment of Kappa coefficients, which ranged between 0.65 and 0.74 . Inter-rater reliability checks were conducted consistently to protect against intra- and inter-rater drift. We also used the query tool in Microsoft Access to analyze specific components of the DET that corresponded with specific study aims. Subsequently, we exported those results to Microsoft Excel and employed the pivot table function to establish descriptive statistics (i.e., frequency counts and proportions) that pertained to each research aim.

\section{Results}

We used five tables to map the key findings of this systematic mapping review. Table 1 details the aims of the six included studies and the characteristics of veteran participants in each study (Aim 1). Table 2 identifies different types of EAAs and EATs that were offered to veterans and presents characteristics of the studied interventions, including identified dosages, providers, 
Table 1 General descriptions of the six filtered studies that primarily focused on equine-assisted interventions

\begin{tabular}{|c|c|c|c|c|c|}
\hline $\begin{array}{l}\text { 1st author } \\
\text { (year) } \\
\text { Country }\end{array}$ & Study aims & Diagnoses and descriptors & $\begin{array}{l}\text { Number of } \\
\text { participants }\end{array}$ & $\begin{array}{l}\text { Number of male } \\
\text { participants (\%) }\end{array}$ & $\begin{array}{l}\text { Age } \\
\text { (year) }\end{array}$ \\
\hline $\begin{array}{l}\text { Lanning } \\
\text { (2013) } \\
\text { United States }\end{array}$ & $\begin{array}{l}\text { To address the need for research } \\
\text { in EAA by assessing the changes } \\
\text { in quality of life indicators and } \\
\text { depression symptoms of veterans } \\
\text { participating in a PATH International } \\
\text { Equine Service for Heroes TR program }\end{array}$ & $\begin{array}{l}\text { PTSD, sexual abuse/trauma, } \\
\text { veteran, physical disabilities }\end{array}$ & $13^{a}$ & $10(76.9)$ & $29-52$ \\
\hline $\begin{array}{l}\text { Nevins (2013) } \\
\text { United States }\end{array}$ & $\begin{array}{l}\text { To investigate the possible } \\
\text { psychological and psychosocial } \\
\text { benefits of teaching a post } \\
\text { deployed veteran the Saratoga } \\
\text { WarHorse Connection method }\end{array}$ & $\begin{array}{l}\text { Veteran, PTSD, } \\
\text { depression, student }\end{array}$ & 1 & $1(100.0)$ & 52 \\
\hline $\begin{array}{l}\text { Duncan } \\
\text { (2014) } \\
\text { Canada }\end{array}$ & $\begin{array}{l}\text { To assess the benefits of participating } \\
\text { in a PTSD-tailored EAL program by } \\
\text { measuring the acquisition of } \\
\text { knowledge in interpersonal skills, } \\
\text { self-mediation, and perceived relief } \\
\text { from PTSD symptoms during } \\
\text { the EAL session using the } \\
\text { HOLSTER and BELT scales }\end{array}$ & Veterans, PTSD, OSI & 58 & $56(96.6)$ & - \\
\hline $\begin{array}{l}\text { Aldridge } \\
\text { (2016) } \\
\text { United States }\end{array}$ & $\begin{array}{l}\text { To compare traditional physical } \\
\text { therapy to hippotherapy combined } \\
\text { with traditional physical therapy } \\
\text { on the motor performance of a } \\
34 \text {-year-old male military } \\
\text { veteran with low back pain. }\end{array}$ & $\begin{array}{l}\text { Veteran, PTSD, } \\
\text { low back } \\
\text { and neck pain }\end{array}$ & 1 & $1(100.0)$ & 34 \\
\hline $\begin{array}{l}\text { Ferruolo } \\
\text { (2016) } \\
\text { United States }\end{array}$ & $\begin{array}{l}\text { To analyze deidentified self-report } \\
\text { evaluation data from participants. }\end{array}$ & Veterans & 8 & $8(100.0)$ & - \\
\hline $\begin{array}{l}\text { Lanning } \\
\text { (2017) } \\
\text { United States }\end{array}$ & $\begin{array}{l}\text { To examine the effects of THR on } \\
\text { PTSD symptoms, quality of life, } \\
\text { and functioning within the ICF framework. }\end{array}$ & Veterans, PTSD & 51 & $33(64.7)$ & $22-57$ \\
\hline
\end{tabular}

${ }^{a}$ Author provided characteristics of the 13 participants who began the intervention, not the seven who completed the entire intervention; BELT Benefitting from Experiential Learning Together, EAA Equine-assisted activities, EAL Equine-assisted learning, HOLSTER Horses Relieving Operational Stress through Experiential Relationships, ICF International Classification System, PATH Professional Association of Therapeutic Horsemanship, PTSD Posttraumatic stress disorder, THR Therapeutic horseback riding, OSI Operational stress injury, TBI Traumatic brain injury. -. Not available

and components of the intervention package (Aim 2). Table 3 elucidates each intervention component (Aim 2 ). Table 4 presents the study designs, outcome measures, and classifications of reported findings pertaining both to their focus and the levels of significance (Aim 3). Table 5 summarizes the theorized benefits of each study (Aim 3). We next elaborate on these findings in more detail.

\section{Aim 1: characteristics of veteran participants}

Five of the six included studies reported participants' health conditions (Table 1). PTSD was reported in all of these five studies, thereby representing the most frequently reported condition. Across the five studies that reported health conditions, PTSD was followed by physical health conditions (two studies), depression (one study), sexual abuse/trauma (one study), and operational stress injury (one study). Four of these studies included participants with multiple health conditions (e.g., PTSD and physical health conditions). Furthermore, two studies were case studies of a veteran experiencing multiple health conditions concurrently. Of the five studies that reported health outcomes, two employed standardized instruments to describe the sample in terms of PTSD symptomatology.

All six studies reported information on participant gender; the majority of veteran participants were male, with proportions ranging from 64.7 to $100 \%$. Four of the six studies reported the age of participants. Veterans across a large portion of the lifespan participated in the seven studies (age range: $22-73$ years).

\section{Aim 2: specific characteristics of equine-assisted activities or therapies \\ Types of equine-assisted activities or therapies}

Four of the six included studies investigated interventions classified as EAAs (Table 2). Across these four studies, two investigated therapeutic horseback riding 
Table 2 A detailed features of equine-assisted interventions in the six filtered studies

\begin{tabular}{|c|c|c|c|c|c|c|}
\hline Items & Lanning (2013) & Nevins (2013) & Duncan (2014) & Aldridge (2016) & Ferruolo (2016) & Lanning (2017) \\
\hline \multicolumn{7}{|l|}{ Type of EAA or EAT } \\
\hline EAA & THR & NOS & EAL & - & - & THR \\
\hline EAT & - & - & - & HPOT & $\mathrm{EFMH}$ & - \\
\hline Provider & - & CT-NOS & - & PT & SW EFMHE & TRI \\
\hline \multicolumn{7}{|l|}{ Sessions } \\
\hline Duration & 24 weeks & 3 days & - & 15 weeks & 1 week & 8 weeks \\
\hline Number of treatment times & 24 & 3 & - & 15 & 2 & 8 \\
\hline Length & $1-2 h$ & $4 \mathrm{~h}$ & - & $1 \mathrm{~h}$ & $7 \mathrm{~h}$ & $1.5 \mathrm{~h}$ \\
\hline Body language and communication & $\checkmark$ & $\checkmark$ & $\checkmark$ & - & $\checkmark$ & $\checkmark$ \\
\hline Ride the horse & $\checkmark$ & - & - & $\checkmark$ & $\checkmark$ & $\checkmark$ \\
\hline Groundwork & $\checkmark$ & $\checkmark$ & - & - & $\checkmark$ & $\checkmark$ \\
\hline Groom the horse & - & - & - & $\checkmark$ & $\checkmark$ & $\checkmark$ \\
\hline Get to know the horse & - & $\checkmark$ & - & - & $\checkmark$ & $\checkmark$ \\
\hline Matching horse and participant & $\checkmark$ & - & - & - & - & $\checkmark$ \\
\hline Care for the horse & - & - & - & $\checkmark$ & - & $\checkmark$ \\
\hline Social activities & $\checkmark$ & - & - & - & - & $\checkmark$ \\
\hline Mounted exercises & - & - & - & $\checkmark$ & $\checkmark$ & - \\
\hline Tack the horse & - & - & - & $\checkmark$ & - & - \\
\hline Safety behaviors & - & $\checkmark$ & - & - & - & - \\
\hline Connections to daily life & - & - & - & - & $\checkmark$ & - \\
\hline Family participation & - & - & $\checkmark$ & - & - & - \\
\hline Integration of therapeutic practices & - & - & - & - & $\checkmark$ & - \\
\hline
\end{tabular}

EAA Equine-assisted activities, EAL Equine-assisted learning, EAT Equine-assisted therapy, EFMH Equine facilitated mental health, HPOT Hippotherapy, NOS Not otherwise specified, THR Therapeutic horseback riding, CT-NOS Certified trainer not otherwise specified, EFMHE Equine facilitated mental health expert, PT Physical therapist, SW Social worker, TRI Therapeutic riding instructor; $\checkmark$ Present; -. Not present

(THR). The average duration of THR was 16 weeks, although considerable dosing variations across the two studies were evident. Only one study of THR explicitly identified a provider [35]. Additionally, across the four studies of EAAs, one study investigated equine-assisted learning (EAL) [36]. This study was conducted in Canada and was the only study conducted outside the United States. While EAL was identified as consisting of three daily four-hour sessions, the duration, number, or length of the EAL was not provided, nor was the provider identified. An EAA that was not otherwise specified (NOS) was investigated in one of the four studies; this study sought to understand the benefits of the Saratoga WarHorse Connection method and identified the provider as a certified trainer [37].

Two of the six studies included investigated the EATs of hippotherapy (HPOT); [38] and Equine-facilitated Mental Health (EFMH) [39]. Both of these studies were conducted in the United States. As illustrated in Table 2, the identified providers and dosages of these two EATs differed substantively.

\section{Components of equine-assisted interventions}

All six studies described components of the intervention (Tables 2 and 3). The number of components described within these studies ranged from two [36] to eight [35, 39 ], with an average of approximately five components $(M=5.33, S D=2.34)$. Generally, the number of components did not differ substantially when comparing the four studies of EAAs $(M=4.75, S D=2.50$, $\min -\max$ : $2-8)$ to the two studies of EATs $(M=6.5, S D=2.12$, $\min$ $-\max$ : 5-8).

The most commonly employed component across the six studies was practicing body language and communication (five of the six studies), followed by riding the horse and groundwork (four of the six studies). While all studies described these and other components, descriptions of the components were generally void of detail. For example, a recent study of THR devoted approximately one paragraph simply to listing components such as riding the horse, grooming the horse, and matching the horse with the participant [35]. Furthermore, the modes of intervention delivery were described in only three studies, with two studies $[37,38]$ specifying an individual session and one study [39] specifying a group session.

While the small number of included studies makes it difficult to discern definitive patterns of differences between EAAs and EATs with respect to intervention components, some differences warrant brief description. 
Table 3 Detailed descriptions of various equine-assisted interventions involved

\begin{tabular}{|c|c|}
\hline Component & Description \\
\hline $\begin{array}{l}\text { Body language and } \\
\text { communication }\end{array}$ & $\begin{array}{l}\text { Verbal and nonverbal language and body } \\
\text { language towards horses or humans }\end{array}$ \\
\hline Ride the horse & $\begin{array}{l}\text { Mounted activities including walking, trotting, } \\
\text { cantering, steering, riding around an obstacle } \\
\text { course, etc. }\end{array}$ \\
\hline Groundwork & $\begin{array}{l}\text { Unmounted activities that involve leading the } \\
\text { horse with or without the halter, work in the } \\
\text { round pen, leading the horse around an } \\
\text { obstacle course, ground exercises such as } \\
\text { stopping, turning, backing up, etc. }\end{array}$ \\
\hline Groom the horse & Grooming, bathing, picking hooves \\
\hline Get to know the horse & $\begin{array}{l}\text { Observing the horse in the pasture or stall, } \\
\text { intentional time spent becoming acquainted } \\
\text { with the horse }\end{array}$ \\
\hline $\begin{array}{l}\text { Matching horse and } \\
\text { participant }\end{array}$ & $\begin{array}{l}\text { Intentional matching, either participant } \\
\text { chooses horse or the instructor/therapist } \\
\text { matches horse to the participant }\end{array}$ \\
\hline Care for the horse & $\begin{array}{l}\text { Feeding, cleaning stalls, turning a horse out or } \\
\text { in from pasture, barn work related to horse } \\
\text { care or article specifically referencing caring for } \\
\text { a horse }\end{array}$ \\
\hline Social activities & $\begin{array}{l}\text { Intentional activities to promote socialization } \\
\text { such as sharing a meal with other veterans or } \\
\text { pairing a veteran volunteer with a participant }\end{array}$ \\
\hline Mounted exercises & $\begin{array}{l}\text { Participant completes stretching and } \\
\text { strengthening exercises while riding the horse } \\
\text { or rides in different positions (sitting } \\
\text { backwards, sideways, or prone) }\end{array}$ \\
\hline Tack the horse & $\begin{array}{l}\text { Activities involving putting tack (bridle, saddle } \\
\text { pad, saddle) on or untacking }\end{array}$ \\
\hline Safety behaviors & Activities focused on safety around the horses \\
\hline $\begin{array}{l}\text { Connections to daily } \\
\text { life }\end{array}$ & $\begin{array}{l}\text { Relating concepts learned from activities with } \\
\text { the horse to the participant's daily life, this } \\
\text { could be through conversation or metaphor }\end{array}$ \\
\hline Family participation & $\begin{array}{l}\text { Spouses or family partners participated during } \\
\text { the session }\end{array}$ \\
\hline $\begin{array}{l}\text { Integration of } \\
\text { therapeutic practices }\end{array}$ & $\begin{array}{l}\text { Implementing other therapeutic methods into } \\
\text { EAAT practice such as cognitive behavioral } \\
\text { therapy, mindfulness-based stress reduction, } \\
\text { motivational interviewing, or reality testing }\end{array}$ \\
\hline
\end{tabular}

Whereas all four studies of EAAs identified practicing body language and communication skills as an intervention component (four studies), only one of the two studies of EAT identified this component. Furthermore, three of the four studies of EAAs emphasized groundwork, while only one of the two studies of EATs included this component. Similarly, two of the four studies of EAAs included matching the horse with participants and social activities compared with none of the two EAT studies. Conversely, while both studies of EATs identified grooming the horse as an intervention component, only one of the four studies of EAAs did so. Both studies of EATs identified riding the horse as a salient aspect of the intervention compared to two of four studies of
EAAs. Finally, the component of mounted exercise was employed in both studies of EATs but was absent among all four studies of EAAs.

\section{Aim 3: characteristics of research on equine-assisted interventions for veterans Study designs}

Five of the six included studies explicitly labeled their study design (Table 4). Of these five studies, all studies used designs consistent with early phase research (i.e., quasi-experimental designs and/or small sample sizes; [40]). Specifically, two of the five studies employed a mixed methods approach integrating a one-group prepost design, two studies used a single-subject case design, and one study used a one-group pre-post design. While these studies were quasi-experimental, two [35, 36] included relatively robust sample sizes (58 and 51 participants), while the remaining had relatively small sample sizes (one to 13 participants). Whereas all six studies analyzed outcomes quantitatively, two studies used a mixed-methods approach that included qualitative analyses of veterans' experiences of the interventions [35, 41]. While one study [39] did not explicitly label its design, our review found that the authors used qualitative data (i.e., responses to open-ended questions) in concert with a descriptive questionnaire (e.g., dichotomous items indicating whether the program eased participant anxiety) to explore the participants' experience of the intervention.

\section{Classifications of reported outcomes}

Four of the six included studies reported specific outcomes that we classified at the ICF-BF level of functioning, most of which pertained to the temperament and personality domain of body functions. Specifically, two studies reported increased confidence, one study reported increased hope, and one study reported outcomes related to coping self-efficacy (from the perspective of both the participant and the participant's partner). One study assessed the attention domain of body functions concerning attending to the present time [35]. The only study that assessed an outcome at this level of functioning pertaining to physical or sensory domains was the study by Aldridge and colleagues [38], which reported outcomes with respect to both neck and back pain. We classified all outcomes at the ICF-BF level of functioning as promising.

Three of the six included studies reported outcomes that we classified at the ICF-AP level of functioning. These outcomes emphasized psychosocial-related phenomena, particularly interpersonal functioning. Outcomes related to interpersonal functioning were heterogeneous and included (but were not limited to) outcomes such as trust in others (three studies), skills 
Table 4 Study designs and outcomes of equine-assisted interventions in the six filtered studies

\begin{tabular}{|c|c|c|c|c|c|}
\hline $\begin{array}{l}1 \text { st } \\
\text { author } \\
\text { (year) }\end{array}$ & Study design & $\begin{array}{l}\text { Assessment } \\
\text { describing } \\
\text { population }\end{array}$ & $\begin{array}{l}\text { Outcome } \\
\text { measures }\end{array}$ & $\begin{array}{l}\text { Outcome } \\
\text { classifications and } \\
\text { levels of significance }\end{array}$ & Reported outcomes \\
\hline \multirow{7}{*}{$\begin{array}{l}\text { Lanning } \\
(2013)\end{array}$} & \multirow[t]{7}{*}{ Mixed methods } & \multirow[t]{7}{*}{-} & $\mathrm{BDI}-\mathrm{II}$ & DSM-V: depression & Decreased symptoms \\
\hline & & & \multirow[t]{2}{*}{ SF-36v2 } & Other & $\begin{array}{l}\text { Quality of life: Physical component (i.e., physical functioning, role } \\
\text { physical, general health); mental component (i.e., vitality, social } \\
\text { functioning, role emotional, mental health) }\end{array}$ \\
\hline & & & & -Other & Quality of life: Bodily pain \\
\hline & & & \multirow{4}{*}{$\begin{array}{l}\text { Semi- } \\
\text { structured } \\
\text { Interview }\end{array}$} & ICF-AP: Interpersonal & $\begin{array}{l}\text { Increased sociability (i.e., forming new relationships), increased } \\
\text { trust in others, more open and accepting of others }\end{array}$ \\
\hline & & & & $\begin{array}{l}\text { ICF-AP: Community } \\
\text { Life }\end{array}$ & Decreased isolation \\
\hline & & & & $\begin{array}{l}\text { ICF-BF: } \\
\text { Temperament }\end{array}$ & Increased confidence \\
\hline & & & & Other & Stronger \\
\hline \multirow{5}{*}{$\begin{array}{l}\text { Nevins } \\
(2013)\end{array}$} & \multirow[t]{5}{*}{ Case study } & \multirow[t]{5}{*}{ CAPS } & $\mathrm{BDI}-\mathrm{II}$ & DSM-V: Depression & Decreased symptoms \\
\hline & & & MSSS & Other & Increased perceived social support \\
\hline & & & $\mathrm{PCL}-\mathrm{C}$ & DSM-V:PTSD & Decreased symptoms \\
\hline & & & QOLI & -Other & $\begin{array}{l}\text { Fluctuating changes in dissatisfaction, happiness, and } \\
\text { satisfaction }\end{array}$ \\
\hline & & & RSES & Other & Resiliency: increased from baseline to 4- and 12-week posttests \\
\hline \multirow{5}{*}{$\begin{array}{l}\text { Duncan } \\
\text { (2014) }\end{array}$} & \multirow{5}{*}{$\begin{array}{l}1 \text { group pre- } \\
\text { post }\end{array}$} & \multirow[t]{5}{*}{-} & \multirow[t]{3}{*}{ BELT } & DSM-V:PTSD & Decreased symptoms as reported by partner \\
\hline & & & & $\begin{array}{l}\text { ICF-BF: } \\
\text { Temperament }\end{array}$ & Increased coping self-efficacy as reported by partner \\
\hline & & & & Other & Partners' feelings towards EAL program \\
\hline & & & \multirow[t]{2}{*}{ HOLSTER } & DSM-V:PTSD & Decreased symptoms as reported by participant \\
\hline & & & & $\begin{array}{l}\text { ICF-BF: } \\
\text { Temperament }\end{array}$ & Increased coping self-efficacy as reported by participant \\
\hline \multirow{3}{*}{$\begin{array}{l}\text { Aldridge } \\
(2016)\end{array}$} & \multirow{3}{*}{$\begin{array}{l}\text { Single-subject } \\
\text { design }\end{array}$} & \multirow[t]{3}{*}{-} & NDI & ICF-BF: Pain & Clinically significant reduction in neck pain \\
\hline & & & OLBPQ & ICF-BF: Pain & Clinically significant reduction in low back pain \\
\hline & & & SDS & - Other & Reduced disability \\
\hline \multirow{5}{*}{$\begin{array}{l}\text { Ferruolo } \\
(2016)\end{array}$} & \multirow[t]{5}{*}{-} & \multirow[t]{5}{*}{-} & \multirow{2}{*}{$\begin{array}{l}\text { Open-ended } \\
\text { questions }\end{array}$} & ICF-AP: Interpersonal & Improved trust, improved respect for others \\
\hline & & & & Other & Learned about self, spiritual connection \\
\hline & & & \multirow[t]{3}{*}{ Questionnaire } & DSM-V: Depression & Self-reported decreased symptoms \\
\hline & & & & DSM-V: Anxiety & Self-reported decreased symptoms \\
\hline & & & & -Other & $\begin{array}{l}\text { No differences in outcomes between those attending } 1 \text { day } \\
\text { versus } 2 \text { days of program }\end{array}$ \\
\hline \multirow{9}{*}{$\begin{array}{l}\text { Lanning } \\
(2017)\end{array}$} & \multirow{9}{*}{$\begin{array}{l}\text { Mixed- } \\
\text { methods, } \\
\text { repeated } \\
\text { measures }\end{array}$} & \multirow[t]{9}{*}{ PCL-M } & PCL-M & - DSM-V: PTSD & Decreased symptoms \\
\hline & & & \multirow[t]{2}{*}{ SF-36V2 } & - Other & $\begin{array}{l}\text { Quality of life: mental component (i.e., vitality, social functioning, } \\
\text { role emotional, mental health) }\end{array}$ \\
\hline & & & & -Other & $\begin{array}{l}\text { Quality of life: physical component (i.e., physical functioning, } \\
\text { role physical, general health) }\end{array}$ \\
\hline & & & \multirow[t]{3}{*}{ WHODAS } & ICF-AP: Interpersonal & $\begin{array}{l}\text { Increased understanding and communication, getting along } \\
\text { with people, participating in society }\end{array}$ \\
\hline & & & & ICF-AP: Self-care & Increased self-care \\
\hline & & & & Other & Reduced disability \\
\hline & & & \multirow{3}{*}{$\begin{array}{l}\text { Semi- } \\
\text { structured } \\
\text { Interview }\end{array}$} & DSM-V: Anxiety & Reduced symptoms \\
\hline & & & & $\begin{array}{l}\text { ICF-BF: } \\
\text { Temperament }\end{array}$ & Improved confidence, increased hope \\
\hline & & & & ICF-BF: Attention & Attending to the present time \\
\hline
\end{tabular}


Table 4 Study designs and outcomes of equine-assisted interventions in the six filtered studies (Continued)

\begin{tabular}{|c|c|c|c|c|c|}
\hline $\begin{array}{l}1 s t \\
\text { author } \\
\text { (year) }\end{array}$ & Study design & $\begin{array}{l}\text { Assessment } \\
\text { describing } \\
\text { population }\end{array}$ & $\begin{array}{l}\text { Outcome } \\
\text { measures }\end{array}$ & $\begin{array}{l}\text { Outcome } \\
\text { classifications and } \\
\text { levels of significance }\end{array}$ & Reported outcomes \\
\hline & & & & ICF-AP: Interpersonal & $\begin{array}{l}\text { Acceptance of self and others, gratitude, increased trust, } \\
\text { improved patience, improved ability to set boundaries }\end{array}$ \\
\hline & & & & ICF-AP: Recreation & Working with horses \\
\hline & & & & $\begin{array}{l}\text { ICF-AP: Non- } \\
\text { remunerative } \\
\text { employment }\end{array}$ & Volunteering for program \\
\hline
\end{tabular}

CAPS. Clinician Administered PTSD Scale, CSES Coping Self Efficacy Scale, DERS Difficulties in Emotion Regulation Scale, DQ Demographic Questionnaire, PCL-M PTSD Checklist Military Version, BDI-II Beck Depression Inventory II, BELT Benefitting from Experiential Learning Together, HOLSTER Horses Relieving Operational Stress through Experiential Relationships, MSSS Modified Social Support Survey, NDI Neck Disability Index, OLBPQ Oswestry Low Back Pain Questionnaire, PCL-C PTSD Checklist Civilian Version, QOLI Quality of Life Inventory, RSES Response to Stressful Experiences Scale, SDS Sheehan Disability Scale, SF-36V2 SF-36v2 Quality of Life Assessment, WHODAS World Health Organization Disability Assessment Schedule, DSM-V Diagnostic \& statistical manual of mental disorders-V, ICF-AP International Classification of Functioning, Disability, and Health (ICF)-Activity/Participation, ICF-BF ICF-Body Functions. $\downarrow$. Statistically significant finding; . Other positive finding; - . Negative finding

related to effective communication (e.g., patience, respect for/getting along with others; three studies), acceptance of oneself and/or others (two studies), and the ability to form new relationships (one study) [35, 39, 41]. Other reported outcomes consistent with the ICF-AP level of functioning concerned community life (i.e., isolation; one study), self-care (one study), recreation (i.e., continued working with horses; one study), and nonremunerative employment (i.e., continued volunteering for the program; one study). Overall, we classified 100\% of all outcomes consistent with the ICF-AP level of functioning as promising findings.

All six studies included at least one outcome categorized as other, and these outcomes were highly variable. Outcomes classified as "other" included but were not limited to quality of life (three studies), disability (two studies), social support (one study), resiliency, learning about oneself, and feelings regarding the intervention itself. The 13 outcomes classified as other were also generally positive, with two outcomes reflecting statistically significant findings, seven outcomes reported to be otherwise promising findings, and the remaining four outcomes classified as negative findings.

Finally, five of the six studies reported outcomes that we classified as relevant to the DSM-V. Of these five studies, PTSD and depressive symptoms were most commonly addressed (three studies each). One study [36] assessed PTSD symptomatology from the perspectives of the participant and the participant's partner. Symptoms of anxiety were the only other reported

Table 5 Theoretical propositions to explain the benefits of equine-assisted interventions in the six filtered studies

\begin{tabular}{|c|c|c|c|c|c|c|}
\hline Items & Lanning (2013) & Nevins (2013) & Duncan (2014) & Aldridge (2016) & Ferruolo (2016) & Lanning (2017) \\
\hline Type of EAA or EAT & THR & NOS & EAL & - & - & THR \\
\hline \multicolumn{7}{|l|}{ EAA } \\
\hline EAT & - & - & - & НРОТ & EFMH & - \\
\hline Horse-human interaction/bond & $\checkmark$ & $\checkmark$ & - & - & - & $\checkmark$ \\
\hline Socialization with others/group reflection & $\checkmark$ & $\checkmark$ & - & - & $\checkmark$ & - \\
\hline Physical features of the equine environment & - & $\checkmark$ & - & - & - & $\checkmark$ \\
\hline Horse as a mirror or metaphor & - & - & - & - & $\checkmark$ & $\checkmark$ \\
\hline Being in the moment/mindfulness & - & - & $\checkmark$ & - & $\checkmark$ & - \\
\hline Safe and nonjudgmental environment & - & - & $\checkmark$ & - & - & $\checkmark$ \\
\hline Experience of control/autonomy & $\checkmark$ & $\checkmark$ & - & - & - & - \\
\hline Opportunity to practice communication & - & - & $\checkmark$ & - & - & - \\
\hline Movement of the horse & - & - & - & $\checkmark$ & - & - \\
\hline Fosters motivation & - & - & - & $\checkmark$ & - & - \\
\hline Cognitive Behavioral Therapy & - & - & - & - & $\checkmark$ & - \\
\hline Calming effect of the horse & $\checkmark$ & - & - & - & - & - \\
\hline Motivational interviewing & - & - & - & - & $\checkmark$ & - \\
\hline Nontraditional therapy setting & - & - & - & - & - & $\checkmark$ \\
\hline
\end{tabular}

THR Therapeutic horseback riding, NOS Not otherwise specified, EAL Equine-assisted learning, HPOT Hippotherapy, EFMH Equine facilitated mental health; $\checkmark$. Present; -. Not present 
outcome that was classified as relevant to the DSM-V and was addressed in two of the five studies. Studies that assessed outcomes consistent with the DSM-V revealed positive findings, with one of the nine findings reflecting a statistically significant reduction in PTSD symptoms [35]. The remaining eight outcomes consistent with the DSM-V were considered to be otherwise promising findings.

\section{Theoretical explanation of benefits}

Fourteen fairly heterogeneous explanations of the benefits of interventions were found across the six studies (Table 5). Individual studies also offered multiple explanations of the benefits of interventions $(M=3.83, S D=$ 1.17, min - max: 2-5). The most commonly reported explanations for positive outcomes pertained to veterans' interactions or bonds with horses and socializing with other humans (three studies). All three studies that invoked the theoretical mechanism of therapeutic bonds between humans and horses were studies of EAAs, two of which studied THR. Furthermore, five of the six studies invoked features of the physical or social environment to explain the positive benefits, such as the aforementioned therapeutic mechanism of socializing with other humans. Two studies also discussed the safe and nonjudgmental nature of the equine context. Furthermore, two studies posited that physical features of the equine environment (e.g., barn, stable, or natural environment) facilitated positive effects.

Although there was relatively little consensus concerning other proposed therapeutic mechanisms, they warrant description. Two of the six studies proposed that using the horse as a mirror or metaphor, being in the moment or being mindful, and experiencing a sense of autonomy explained the positive benefits of the studied interventions. One study employed established therapeutic approaches (i.e., cognitive behavioral therapy and motivational interviewing) to explain positive outcomes. Other explanations invoked in only one study included harnessing the horse's movement to stimulate sensorimotor functions, enhancing motivation, affording opportunities to practice communication skills, the calming effect of the horse, and the nontraditional nature of the equine-assisted therapy setting.

\section{Discussion}

Using the method of a systematic mapping review, we found promising evidence that some EAAs and EATs may benefit veterans with service-related injuries, in particular those that targeted psychosocial outcomes. At the same time, the body of literature that provided this evidence is sparse and reflects very early scientific development. We next elaborate on the nature of promising findings, as well as gaps in knowledge and needed future research steps.

Established treatments that target psychosocial outcomes such as exposure-based therapy are not effective for up to $50 \%$ of veterans $[15,16]$. The evidence gleaned through this systematic mapping review indicates that equine-assisted interventions warrant continued scientific investment to establish their efficacy as additional treatment approaches for veterans with psychosocial difficulties. For example, an included study of THR observed statistically significant reductions in veterans' experience of PTSD symptoms and a corresponding improvement in general psychosocial functioning (e.g., improved social functioning and reduced barriers to role fulfillment) [35]. Other promising findings indicate a positive impact of the Saratoga WarHorse project, EAL, and EFMH on depressive symptoms [37, 39], coping ability [36], and anxiety [35, 39].

While all studies employed some form of quantitative methods, three studies $[35,39,41]$ integrated qualitative data, thereby shedding light on veterans' subjective experience of equine-assisted interventions. Qualitative findings substantiated the aforementioned psychosocial benefits by documenting decreased anxiety [35] and improved social functioning (e.g., improved ability to form new relationships; [41]). In addition, qualitative methods yielded insight into an expanded view of outcomes that may be targeted in future inquiry. In particular, all three of these studies offered a more refined view of the benefits of equine-assisted interventions on social functioning. Veterans reported that the interventions resulted in increased trust, patience, gratitude, and respect for others, as well as an improved ability to set boundaries during social interactions. This refined knowledge of how equine-assisted interventions may benefit social functioning reflects an important contribution to the existing literature by encouraging a more precise assessment of outcomes, thereby fostering ongoing theoretical and empirical development.

Qualitative findings also yielded interesting results with respect to self-referential outcomes and suggest that equine-assisted interventions may encourage veterans to endorse a more positive appraisal of themselves and their relationship with the world. For example, veterans in two studies $[35,41]$ reported that the intervention improved their overall confidence. In addition, veterans reported learning about themselves [39] and an increased acceptance of themselves [35]. Importantly, outcomes that reflect a more positive appraisal of themselves (e.g., self-efficacy and self-esteem) have been identified as a fruitful target for rehabilitative efforts [42] and are considered critical for psychological wellbeing [43, 44]. Increased attention to self-referential outcomes such as self-efficacy may be particularly important to veterans, 
many of whom negatively appraise their abilities as significant barriers to community reintegration [45]. Future studies of equine-assisted interventions for the veteran population should therefore emphasize self-referential outcomes within theoretical and empirical development efforts.

Finally, qualitative findings indicated that equineassisted interventions may produce improved engagement in the civilian community, which veterans indicate is a common challenge upon detachment from the military $[9,11]$. For example, veterans in the included studies reported a decreased sense of isolation [41] and increased engagement in recreational activities and volunteering [35]. These qualitative findings, along with the aforementioned findings with respect to improved role fulfillment [35], suggest that equine-assisted interventions may be capable of supporting veterans' community reintegration, a rehabilitative outcome of utmost importance for the veteran population [46, 47]. However, the majority of the included studies did not consider the impact of the intervention on individualized patterns of engagement in the civilian community or the extent to which those patterns of engagement aligned with veterans' values and interests. For example, for veterans with children, a relevant and valued outcome may be shared engagement in activities with their children. Conversely, this same outcome may not be relevant for veterans without families. Future studies should target and assess outcomes related to the individualized and subjective experience of engagement in the community because engagement in activities that align with one's personal values and interests is considered a critical ingredient for psychological wellbeing $[48,49]$.

\section{Next research steps}

Future studies may benefit from targeting a more expansive range of outcomes including but not limited to outcomes consistent with the complex and unpredictable nature of polytraumatic injuries. Future studies must also address gaps with respect to theoretical development, descriptions of participants and the intervention, factors influencing attrition, and the dose-response relationship.

The reviewed studies reflected a disproportionate emphasis on the influence of equine-assisted interventions on psychosocial outcomes and generally overlooked the multifaceted concerns of veterans with polytraumatic injuries that transcend both psychosocial and physical domains (e.g., pain; [5, 50]). Clearly, psychosocial functioning is a critical target for intervention, but the physical challenges faced by veterans similarly disrupt their successful transition to civilian life [11, 13]. For example, the rates of pain among returning post-9/11 veterans are alarming, ranging from 47 to $89 \%$ [51, 52].
Furthermore, pain tends to co-occur with psychiatric conditions such as PTSD, with one study documenting that $66 \%$ of their sample with PTSD reported comorbid chronic pain [53]. Unfortunately, despite evidence suggesting that equine-assisted interventions can positively influence physical domains such as pain [54-56], our review found only one study that investigated similar outcomes in the veteran population. This single-subject study [38] documented positive results, including reductions in pain and corresponding reductions in disability. While this study yielded promising results, there is a persistent need for the development of equine-assisted interventions among the veteran population that fully unleash their potential as complex interventions [2123]. Specifically, future efforts should develop an understanding of how to precisely tailor equine-assisted interventions to address the complex and individualized patterns of psychosocial and physical impairments experienced by veterans with polytraumatic injuries [2].

While the existing evidence offers promise for the efficacy of equine-assisted interventions for the veteran population, it is imperative that empirical support for such interventions continues to develop. The paucity of studies investigating the impact of equine-assisted interventions for veterans does not correspond to the rapid proliferation of such interventions available to veterans [20]. The state of the evidence is most consistent with early phases of scientific development, consisting of quasi-experimental and case study designs [23, 40]. Ongoing establishment of such evidence is critical, especially given that there were over 300 programs delivering equine-assisted interventions for veterans in 2016 [20]. Notably, while they did not meet our inclusion criteria due to their publication after 2017, three recent studies [57-59] employed controlled trial designs, which are methods consistent with more mature phases of scientific development. These studies bolstered reviewed findings by observing statistically significant reductions in PTSD symptoms. However, our review revealed that significant gaps in knowledge remain and must be addressed to facilitate the identification of interventions most worthy of widespread implementation among veterans.

A foundational component of developing and evaluating an intervention is to propose and test the underlying theory concerning the mechanism by which an intervention influences targeted outcomes [23, 40]. Theoretical development is a necessary step that informs translation of research findings into practice by shedding light on how the intervention produces change and for whom, thereby guiding efforts to refine the intervention to ensure its safe and effective delivery [60]. Unfortunately, the state of theoretical development regarding the mechanisms by which equine-assisted interventions benefit 
the veteran population is currently insufficient. The present review summarized authors' proposals of 14 distinct mechanisms by which equine-assisted interventions benefit veterans, highlighting the lack of consensus across the body of literature. There is a need for deliberate efforts to foster a more parsimonious understanding of the proposed benefits of equine-assisted interventions among the veteran population, thereby enabling more focused inquiry into the mechanisms by which observed outcomes are achieved and more precisely guiding efforts that maximize the interventions' efficacy.

While all of the included studies offered theorized explanations for the benefits of equine-assisted interventions for veterans, few integrated their proposed mechanisms into the study design in a way that offered empirical support for their propositions. While it was not their stated objective, only three studies $[35,38,41]$ used qualitative data to access veterans' experience of the intervention, thereby offering evidence capable of advancing theoretical development [61]. Future inquiry should involve 1) proposing a particular therapeutic mechanism (e.g., interacting with the horse fulfills emotional needs), 2) testing the intervention's ability to elicit those benefits (e.g., assessing emotional needs fulfillment during intervention), and 3) attempting to link those benefits to targeted outcomes. Engaging in such a process is a critical component of assessing intervention effects and would help advance the iterative process of theoretical development by discarding proposed mechanisms that fail to garner empirical support $[62,63]$.

Existing evidence offers glimpses of potentially fruitful targets for theoretical development. Five out of six studies identified a feature of the social and/or physical environment as a potential mechanism by which equineassisted interventions produce positive outcomes, suggesting that the unique and supportive aspects of the equine context may be a therapeutic mechanism. In particular, the review suggests that the social aspects of the equine context offer a safe and nonjudgmental environment in which to develop interpersonal skills and secure supportive connections with other humans [35-37, 39, 41]. Indeed, a recent study that did not meet inclusion criteria due to its publication in 2018 found that incorporating veterans' partners into an equine-assisted intervention offered unique benefits [64]. In addition, the horse-human bond was identified in $50 \%$ of the reviewed studies and may also be a fruitful target for theoretical development. Conceptual work elucidating the unique benefits of the horse-human bond [65] indicates that veterans with psychiatric conditions such as PTSD can more easily establish a connection with a horse compared to humans, thereby fulfilling emotional needs. Furthermore, horses are hypervigilant and sensitive to nonverbal cues; interacting with horses tends to encourage veterans to foster awareness of outward expressions of emotional dysregulation (e.g., aggressive movements) and translate that awareness to human interaction.

The above proposed mechanisms indicate that theoretical development for equine-assisted interventions among veterans may benefit from adopting conceptual frameworks that recognize the power of context in supporting desired outcomes [66, 67]. For example, such frameworks can be used to understand how the supportive and interactive qualities of the equine context may be capable of addressing the paradoxical relationship between psychiatric conditions and the supportive presence of others among veterans. On the one hand, the supportive presence of others is considered a buffer against PTSD [68], depression [69], and suicidal behavior [70]. On the other hand, the cognitive and emotional impairments that often accompany psychiatric conditions tend to limit the interpersonal skills veterans must employ to secure these critical connections with others $[11,71]$. The safe and nonjudgmental nature of the equine context may offer an opportunity to interact with and secure support from other humans (i.e., participants and staff). Similarly, interacting with the horse offers an opportunity to experience an emotional connection and develop critical interpersonal skills in a nonthreatening context.

Among the reviewed studies, the aspect of theoretical development related to who benefits from intervention would benefit from a more comprehensive profile of veteran participants [63]. For example, of the six reviewed studies, only two $[35,37]$ included a standardized assessment of PTSD symptoms to understand their respective samples. Furthermore, neither of those studies offered a precise profile of the pattern of PTSD symptoms experienced by the participants, despite evidence [72] suggesting that veterans tend to experience a unique pattern of one or more of the following distinct symptom clusters: re-experiencing (e.g., emotional reactivity to trauma cues); avoidance (e.g., avoidance of thoughts); dysphoria (e.g., detachment); and hyperarousal (e.g., hypervigilance). Future research should include a detailed profile of veterans' experience of the above symptom clusters, which may subsequently guide individualization of the intervention to target particular manifestations of symptom patterns. For example, a veteran experiencing the dysphoria symptom cluster may benefit from equineassisted intervention that emphasizes facilitating a connection with the horse or other humans to address a sense of detachment. For veterans reporting symptoms consistent with the re-experiencing symptom cluster, intervention may emphasize using the horse's sensitivity to outward expressions of emotional dysregulation to foster awareness of reactivity to trauma cues, a critical 
component of developing effective coping skills [73]. Similarly, none of the included studies sought to systematically understand the presence of comorbid conditions in their sample (e.g., depression and/or TBI). Given that PTSD often co-occurs with other diagnoses such as depression and TBI among veterans [2], future work should seek to understand how equine-assisted interventions can be individualized to address particular combinations of comorbid health conditions and whether responses to treatment vary according to particular combinations of comorbid conditions.

Current evidence for equine-assisted interventions for veterans would also be strengthened by a more comprehensive and thorough description of the intervention being tested. While all six studies listed the intervention components, these studies provided insufficient detail with respect to important aspects of describing an intervention, including the therapeutic goal of each individual component, whether the intervention was intended to be personalized or adapted to achieve individualized objectives, and to what extent intervention fidelity was achieved [74]. A more thorough description of the intervention would support the process of theoretical development by describing and testing an explicit link from one or more components of the intervention to therapeutic goals [63]. Furthermore, a more thorough description of the intervention and an evaluation of treatment fidelity can support successful implementation of the intervention by facilitating the identification of potential barriers to implementation and by providing clinicians with the detail required to employ a novel intervention in routine clinical practice $[23,74]$.

The implementation of equine-assisted interventions for veterans would also be supported by a greater understanding of both the factors contributing to attrition and the dose-response relationship. Only two included studies reported attrition rates, with one reporting a rate of $24 \%$ [35] and the other reporting a rate of $46 \%$ [41]. Furthermore, only one of these studies [41] reported factors explaining attrition, which included participants moving or becoming too busy to attend sessions. A more comprehensive understanding of the reasons for attrition would facilitate the execution of appropriate modifications to support the successful implementation of equine-assisted interventions for veterans. Finally, the paucity of studies, combined with the highly variable duration and length of included studies (see Table 2), precludes an accurate understanding of the most efficient dose-response relationship for equine-assisted interventions for veterans. An understanding of the optimal amount of treatment that tends to generate desired outcomes is a critical component of developing and evaluating interventions and must be achieved to ensure cost-effective, safe, and effective services for veterans $[40,63]$.

\section{Limitations}

The search procedure employed in this study was sufficiently broad in scope to retrieve papers related to equineassisted interventions among veterans, but we may have missed sources not indexed in databases targeted by our search or articles that were indexed after the final search in 2018. Indeed, we briefly addressed several articles [5759,64 that were published too recently to be included in this review. Because we restricted our search to studies published in the English language, we may have excluded pertinent studies written in other languages. Systematic mapping reviews do not typically include the formal assessment of the rigor of included studies, and as such, we did not conduct such an assessment. An assessment of the methodological quality of each individual study may be a worthy pursuit in future research. Finally, the representations of equine-assisted interventions among veterans included in this review were derived from peer-reviewed research studies and should not be considered a comprehensive reflection of the nature of equine-assisted interventions for veterans.

\section{Conclusions}

Ideally, the approach to developing, evaluating, and implementing novel and complex equine-assisted interventions for the veteran population would be systematic and phased, beginning with a thorough understanding of the existing literature. However, while over 300 programs currently deliver equine-assisted services to veterans [20], little is known regarding the safe and effective delivery of such services. This systematic mapping review consequently sought to develop a comprehensive map of the body of evidence concerning equineassisted interventions for veterans. Because various equine-assisted interventions that targeted psychosocial outcomes among veterans were found to be promising, they warrant continued scientific investment to help establish their efficacy. However, considerable gaps in knowledge or research approaches must also be addressed. Specifically, targeted outcomes should be expanded to include those consistent with polytraumatic injuries, including concurrent psychosocial (e.g., PTSD symptoms) and physical (e.g., pain) concerns. More nuanced perspectives on qualities of social functioning, self-referential outcomes (e.g., self-efficacy), and community reintegration are also needed. Future studies must also emphasize the theoretical development of equineassisted interventions for veterans and thoroughly describe the participants, components of the intervention, factors contributing to attrition, and optimal dose-response relationships. Advancing knowledge of these phenomena will facilitate the identification of those interventions most worthy of widespread implementation on behalf of the veteran population. 


\section{Abbreviations}

AAls: Animal-assisted interventions; BDI-II: Beck Depression Inventory II; BELT: Benefitting from Experiential Learning Together; CAPS: Clinician Administered PTSD Scale; CSES: Coping Self Efficacy Scale; CT-NOS: Certified trainer not otherwise specified; DERS: Difficulties in Emotion Regulation Scale; DET: Data extraction tool; DQ: Demographic Questionnaire; DSMV: Diagnostic and Statistical Manual of Mental Disorders, Fifth Edition; EAAs: Equine-assisted activities; EAL: Equine-assisted learning; EATs: Equineassisted therapies; EFMH: Equine facilitated mental health, EFMHE: Equine facilitated mental health expert; HOLSTER: Horses Relieving Operational Stress through Experiential Relationships; HPOT: Hippotherapy; ICF: International Classification of Functioning, Disability, and Health; ICF-A/ P: Activity/participation; ICF-BF: Body functions; MSSS: Modified Social Support Survey; NDI: Neck Disability Index; NOS: Not otherwise specified; OLBPQ: Oswestry Low Back Pain Questionnaire; OSI: Operational stress injury; PATH Intl: Professional Association of Therapeutic Horsemanship International; PCL-C: PTSD Checklist Civilian Version; PCL-M: PTSD Checklist Military Version; PT: Physical therapist; PTSD: Posttraumatic stress disorder; QOLI: Quality of Life Inventory; RSES: Response to Stressful Experiences Scale; SDS: Sheehan Disability Scale; SF-36v2: SF-36v2 Quality of Life Assessment; SW: Social worker; TBI: Traumatic brain injury; THR: Therapeutic horseback riding; TRI: Therapeutic riding instructor; WHODAS: World Health Organization Disability Assessment Schedule

\section{Acknowledgements}

We thank Christof Bentele, MS, OTR/L, for his assistance with data collection. We thank B. Caitlin McDaniel Peters, PhD, OTR/L, for reviewing an early draft of this manuscript

\section{Authors' contributions}

The first author participated in the analysis of the included papers and took a lead role in the development of this manuscript. The second author participated in the analysis of the included papers and contributed to the development of this manuscript. The third author led data collection and contributed to the development of this manuscript. The last author was the $\mathrm{Pl}$ of the larger systematic mapping review for all populations and contributed to the development of this manuscript. All authors read and approved the final manuscript.

\section{Funding}

This study was funded by the Carl and Caroline Swanson Foundation. Support was also provided through philanthropic support of the New Start for Student Veterans program by a private donor.

\section{Availability of data and materials}

Not applicable.

\section{Ethics approval and consent to participate}

This article does not contain any studies with human participants or animals performed by any of the authors.

\section{Consent for publication}

This manuscript does not contain any individual person's data.

\section{Competing interests}

The authors declare that they have no competing interests.

\section{Author details}

'Department of Occupational Therapy, Colorado State University, Fort Collins, CO 80523, USA. ${ }^{2}$ Temple Grandin Equine Center, Department of Animal Sciences, Colorado State University, Fort Collins, CO 80523, USA.

Received: 20 March 2019 Accepted: 8 August 2019

Published online: 29 August 2019

\section{References}

1. Wenger JW, O'Connell C, Cottrell L. Examination of recent deployment experience across the services and components. Santa Monica: RAND Corporation; 2018.
2. Brenner LA, Vanderploeg RD, Terrio H. Assessment and diagnosis of mild traumatic brain injury, posttraumatic stress disorder, and other polytrauma conditions: burden of adversity hypothesis. Rehabil Psychol. 2009;54:239-46.

3. Thomas JL, Wilk JE, Riviere LA, McGurk D, Castro CA, Hoge CW. Prevalence of mental health problems and functional impairment among active component and national guard soldiers 3 and 12 months following combat in Iraq. Arch Gen Psychiatry. 2010;67:614-23.

4. Wilk JE, Herrell RK, Wynn GH, Riviere LA, Hoge CW. Mild traumatic brain injury (concussion), posttraumatic stress disorder, and depression in US soldiers involved in combat deployments: association with postdeployment symptoms. Psychosom Med. 2012;74(3):249-57.

5. Hoge CW, Terhakopian A, Castro CA, Messer SC, Engel CC. Association of posttraumatic stress disorder with somatic symptoms, health care visits, and absenteeism among Iraq war veterans. Am J Psychiatry. 2007;164:150-3.

6. Tanielian T, Haycox LH, Schell TL, Marshall GN, Burnam MA, Eibner C, et al. Invisible wounds of war: summary and recommendations for addressing psychological and cognitive injuries. Santa Monica: RAND Corporation; 2008.

7. Pugh MJ, Swan AA, Carlson KF, Jaramillo CA, Eapen BC, Dillahunt-Aspillaga $C$, et al. Traumatic brain injury severity, comorbidity, social support, family functioning, and community reintegration among veterans of the Afghanistan and Iraq wars. Arch Phys Med Rehabil. 2018;99(2):S40-9.

8. Sayers SL, Farrow VA, Ross J, Oslin DW. Family problems among recently returned military veterans referred for a mental health evaluation. J Clin Psychiatry. 2009;70(2):163.

9. Resnik L, Gray M, Borgia M. Measurement of community reintegration in sample of severely wounded servicemembers. J Rehabil Res Dev. 2011;48(2): 89-102.

10. Sayer NA, Noorbaloochi S, Frazier P, Carlson K, Gravely A, Murdoch M. Reintegration problems and treatment interests among Iraq and Afghanistan combat veterans receiving VA medical care. Psychiatr Serv. 2010;61(6):589-97.

11. Resnik $L$, Allen SM. Using international classification of functioning, disability and health to understand challenges in community reintegration of injured veterans. J Rehabil Res Dev. 2007;44(7):991-1006.

12. Daggett VS, Bakas T, Buelow J, Habermann B, Murray LL. Needs and concerns of male combat veterans with mild traumatic brain injury. J Rehabil Res Dev. 2013;50(3):327-40.

13. Seal KH, Bertenthal D, Barnes DE, Byers AL, Strigo I, Yaffe K. Association of traumatic brain injury with chronic pain in Iraq and Afghanistan veterans: impact of comorbid mental health conditions. Arch Phys Med Rehabil. 2017; 98(8):1636-1645.

14. Insitute of Medicine. Treatment of posttraumatic stress disorder: an assessment of the evidence. Washington, DC: The National Academies Press; 2008.

15. Resick PA, Nishith P, Weaver TL, Astin MC, Feuer CA. A comparison of cognitive-processing therapy with prolonged exposure and a waiting condition for the treatment of chronic posttraumatic stress disorder in female rape victims. J Consult Clin Psychol. 2002;70(4):867-79.

16. Schnurr PP, Friedman MJ, Engel CC, Foa EB, Shea MT, Chow BK, et al. Cognitive behavioral therapy for posttraumatic stress disorder in women: a randomized controlled trial. JAMA. 2007;297(8):820-30.

17. Lang AJ, Schnurr PP, Jain S, Raman R, Walser R, Bolton E, et al. Evaluating transdiagnostic treatment for distress and impairment in veterans: a multisite randomized controlled trial of acceptance and commitment therapy. Contemp Clin Trials. 2012;33(1):116-23.

18. American Veterinary Medical Association. Animal-assisted interventions: definitions; 2018. https://www.avma.org/KB/Policies/Pages/Animal-AssistedInterventions-Definitions.aspx?PF=1. Accessed 20 July 2018.

19. Professional Association of Therapeutic Horsemanship International. EAAT definitions 2017. https://www.pathintl.org/resources-education/resources/ eaat/193-eaat-definitions. Accessed 14 June 2018.

20. Professional Association of Therapeutic Horsemanship International. 2016 PATH Intl Statistics 2016. https://www.pathintl.org/images/pdf/about-narha/ documents/2016-fact-sheet-for-web.pdf. Accessed 14 June 2018.

21. Peters BCM, Wood W. Autism and equine-assisted interventions: a systematic mapping review. J Autism Dev Disord. 2017;47(10):3220-42.

22. Wood WH, Fields BE. Hippotherapy: a systematic mapping review of peerreviewed research, 1998 to 2015. Disabil Rehabil. under review.

23. Craig P, Dieppe P, Macintyre S, Michie S, Nazareth I, Petticrew M. Developing and evaluating complex interventions: the new Medical Research Council guidance. BMJ. 2008;337:a1655.

24. Erdman EA, Pierce SR. Use of hippotherapy with a boy after traumatic brain injury: a case study. Pediatr Phys Ther. 2016;28(1):109-16. 
25. Cantin A, Marshall-Lucette S. Examining the literature on the efficacy of equine assisted therapy for people with mental health and behavioural disorders. Ment Health Learn Disabil Res Pract. 2011;8(1):51-61.

26. Lechner HE, Kakebeeke TH, Hegemann D, Baumberger M. The effect of hippotherapy on spasticity and on mental well-being of persons with spinal cord injury. Arch Phys Med Rehabil. 2007;88(10):1241-8.

27. Mueller M, McCullough L. Effects of equine-facilitated psychotherapy on post-traumatic stress symptoms in youth. J Child Fam Stud. 2017;26(4): 1164-72.

28. Hammick M. A BEME review: a little illumination. Med Teach. 2005;27(1):1-3.

29. Grant MJ, Booth A. A typology of reviews: an analysis of 14 review types and associated methodologies. Health Info Libr J. 2009;26(2):91-108.

30. Wood W, Fields B, Rose M, McLure M. Animal-assisted therapies and dementia: a systematic mapping review using the Lived Environment Life Quality (LELQ) model. Am J Occup Ther. 2017;71(5):7105190030p1-10.

31. King R, Hooper B, Wood W. Using bibliographic software to appraise and code data in educational systematic review research. Med Teach. 2011;33(9):719-23.

32. Hammick M, Dornan T, Steinert Y. Conducting a best evidence systematic review. Part 1: from idea to data coding. BEME guide no. 13. Med Teach. 2010;32(1):3-15.

33. World Health Organization. International classification of functioning, disability, and health. Geneva: World Health Organization; 2001.

34. American Psychiatric Association. Diagnostic and statistical manual of mental disorders (DSM-5 ${ }^{\oplus}$ ): American psychiatric pub; 2013.

35. Lanning BA, Wilson AL, Krenek N, Beaujean AA. Using therapeutic riding as an intervention for combat veterans: an international classification of functioning, disability, and health (ICF) approach. Occup Ther Ment Health. 2017;33(3):259-78.

36. Duncan CR, Critchley S, Marland J. Can praxis: a model of equine assisted learning (EAL) for PTSD. Can Mil J. 2014;14(2):64-9.

37. Nevins R, Finch S, Hickling EJ, Barnett SD. The Saratoga WarHorse project: a case study of the treatment of psychological distress in a veteran of operation Iraqi freedom. Adv Mind Body Med. 2013;27(4):22-5.

38. Aldridge RL, Morgan A, Lewis A. The effects of hippotherapy on moto performance in veterans with disabilities: a case report. J Mil Veterans Health. 2016;24(3):24-7.

39. Ferruolo DM. Psychosocial equine program for veterans. Soc Work. 2016; 61(1):53-60.

40. Whyte J, Barrett A. Advancing the evidence base of rehabilitation treatments: a developmental approach. Arch Phys Med Rehabil. 2012;93(8):S101-10.

41. Lanning BA, Krenek N. Examining effects of equine-assisted activities to help combat veterans improve quality of life. J Rehabil Res Dev. 2013;50(8):vii-xiii.

42. King GA. The meaning of life experiences: application of a meta-model to rehabilitation sciences and services. Am J Orthop. 2004;74(1):72-88.

43. Ryff CD. Happiness is everything, or is it? Explorations on the meaning of psychological well-being. J Pers Soc Psychol. 1989;57(6):1069-81.

44. Deci EL, Ryan RM. The "what" and "why" of goal pursuits: human needs and the self-determination of behavior. Psychol Inq. 2000;11(4):227-68.

45. Hawkins BL, McGuire FA, Linder SM, Britt TW. Understanding contextual influences of community reintegration among injured servicemembers. J Rehabil Res Dev. 2015;52(5):527-42.

46. Resnik L, Bradford DW, Glynn SM, Jette AM, Hernandez CJ, Wills S. Issues in defining and measuring veteran community reintegration: proceedings of the working group on community reintegration, VA rehabilitation outcomes conference, Miami, Florida. J Rehabil Res Dev. 2012;49(1):87.

47. Crocker T, Powell-Cope G, Brown LM, Besterman-Dahan K. Toward a veteran-centric view on community (re) integration. J Rehabil Res Dev. 2014;51(2):xi-xvii.

48. Eakman AM. Relationships between meaningful activity, basic psychological needs, and meaning in life: test of the meaningful activity and life meaning model. OTJR. 2013;33(2):100-9.

49. Eakman AM. A prospective longitudinal study testing relationships between meaningful activities, basic psychological needs fulfillment, and meaning in life. OTJR. 2014;34(2):93-105.

50. Polusny MA, Kehle SM, Nelson NW, Erbes CR, Arbisi PA, Thuras P. Longitudinal effects of mild traumatic brain injury and posttraumatic stress disorder comorbidity on postdeployment outcomes in national guard soldiers deployed to Iraq. Arch Gen Psychiatry. 2011;68(1):79-89.

51. Gironda RJ, Clark ME, Massengale JP, Walker RL. Pain among veterans of operations enduring freedom and Iraqi freedom. Pain Med. 2006;7(4): 339-43.
52. Lang KP, Veazey-Morris K, Andrasik F. Exploring the role of insomnia in the relation between PTSD and pain in veterans with polytrauma injuries. J Head Trauma Rehabil. 2014;29(1):44-53.

53. Shipherd JC, Keyes M, Jovanovic T, Ready DJ, Baltzell D, Worley V, et al. Veterans seeking treatment for posttraumatic stress disorder: what about comorbid chronic pain? J Rehabil Res Dev. 2007:44:153-66.

54. Hammer A, Nilsagard Y, Forsberg A, Pepa H, Skargren E, Oberg B. Evaluation of therapeutic riding (Sweden)/hippotherapy (United States). A singlesubject experimental design study replicated in eleven patients with multiple sclerosis. Physiother Theory Pract. 2005;21(1):51-77.

55. Korhonen T, Mattila-Rautainen S, Nyman M, Tossavainen S. An experimental study of the effects of riding with chronic low back pain patients. Sci Educ J Ther Riding. 2008;1(1):45-50.

56. Håkanson M, Moller M, Lindstrom I, Mattsson B. The horse as the healer--a study of riding in patients with back pain. J Bodyw Mov Ther. 2009;13(1):43-52.

57. Johnson RA, Albright DL, Marzolf JR, Bibbo JL, Yaglom HD, Crowder SM, et al. Effects of therapeutic horseback riding on post-traumatic stress disorder in military veterans. Mil Med Res. 2018;5:3.

58. Burton LE, Qeadan F, Burge MR. Efficacy of equine-assisted psychotherapy in veterans with posttraumatic stress disorder. J Integr Med. 2019;17(1):14-9.

59. Lanning BA, Wilson AL, Woelk R, Beaujean AA. Therapeutic horseback riding as a complementary intervention for military service members with PTSD. Hum Anim Interact Bull. 2018;6(2):58-82.

60. Sidora-Arcoleo K, McClain DB. Explaining intervention effects. In: Melnyk BM, Morrison-Beedy D, editors. Intervention research: designing, conducting, analyzing, and funding. New York: Springer; 2012. p. 343-60.

61. Nastasi BK, Schensul SL. Contributions of qualitative research to the validity of intervention research. J Sch Psychol. 2005;43(3):177-95.

62. Melnyk BM, Morrison-Beedy D. Intervention research: designing, conducting, analyzing, and funding. New York: Springer; 2012. p. 315-30.

63. Melnyk BM, Morrison-Beedy D. Intervention research: designing, conducting, analyzing, and funding. New York: Springer; 2012. p. 11-36.

64. Romaniuk M, Evans J, Kidd C. Evaluation of an equine-assisted therapy program for veterans who identify as 'wounded, injured or ill'and their partners. PLoS One. 2018;13(9):e0203943.

65. MacLean B. Guest editorial. Equine-assisted therapy. J Rehabil Res Dev. 2011; 48(7):ix-xii.

66. Wood W, Lampe JL, Logan CA, Metcalfe AR, Hoesly BE. The lived environment life quality model for institutionalized people with dementia. Can J Occup Ther. 2017;84(1):22-33.

67. Law M, Cooper B, Strong S, Stewart D, Rigby P, Letts L. The personenvironment-occupation model: a transactive approach to occupational performance. Can J Occup Ther. 1996;63(1):9-23.

68. Polusny MA, Erbes CR, Murdoch M, Arbisi PA, Thuras P, Rath M. Prospective risk factors for new-onset post-traumatic stress disorder in National Guard soldiers deployed to Iraq. Psychol Med. 2011;41(4):687-98.

69. Pietrzak RH, Goldstein MB, Malley JC, Johnson DC, Southwick SM. Subsyndromal posttraumatic stress disorder is associated with health and psychosocial difficulties in veterans of operations enduring freedom and Iraqi freedom. Depress Anxiety. 2009;26(8):739-44.

70. Lemaire CM, Graham DP. Factors associated with suicidal ideation in OEF/ OIF veterans. J Affect Disord. 2011;130(1):231-8.

71. Shallcross SL, Arbisi PA, Polusny MA, Kramer MD, Erbes CR. Social causation versus social erosion: comparisons of causal models for relations between support and PTSD symptoms. J Trauma Stress. 2016;29(2):167-75.

72. Pietrzak RH, Goldstein MB, Malley JC, Rivers AJ, Southwick SM. Structure of posttraumatic stress disorder symptoms and psychosocial functioning in veterans of operations enduring freedom and Iraqi freedom. Psychiatry Res. 2010;178(2):323-9.

73. Lazarus RS, Folkman S. Stress, appraisal, and coping. New York: Springer; 1984.

74. Hoffmann TC, Walker MF, Langhorne P, Eames S, Thomas E, Glasziou P. What's in a name? The challenge of describing interventions in systematic reviews: analysis of a random sample of reviews of non-pharmacological stroke interventions. BMJ Open. 2015;5(11):e009051. 